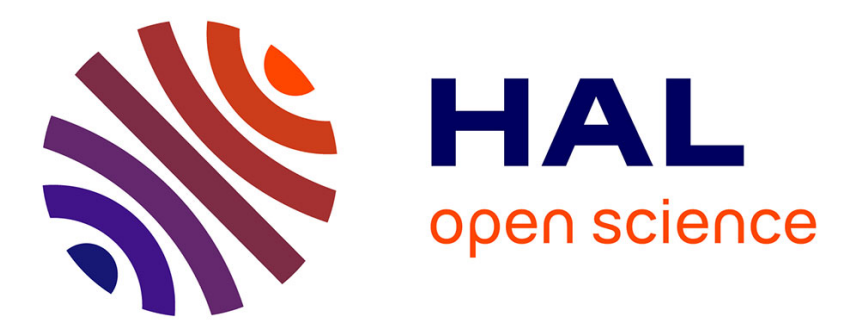

\title{
Observations of dry particles behaviour at the tyre/road interface
}

\author{
Simon Changarnier, Yosra Hichri, Veronique Cerezo, Minh Tan Do, \\ Ferdinando Salvatore, Hassan Zahouani
}

\section{- To cite this version:}

Simon Changarnier, Yosra Hichri, Veronique Cerezo, Minh Tan Do, Ferdinando Salvatore, et al.. Observations of dry particles behaviour at the tyre/road interface. Tribology International, 2018, 128, pp.291-301. 10.1016/j.triboint.2018.07.023 . hal-01851867

\section{HAL Id: hal-01851867 https://hal.science/hal-01851867}

Submitted on 31 Jul 2018

HAL is a multi-disciplinary open access archive for the deposit and dissemination of scientific research documents, whether they are published or not. The documents may come from teaching and research institutions in France or abroad, or from public or private research centers.
L'archive ouverte pluridisciplinaire HAL, est destinée au dépôt et à la diffusion de documents scientifiques de niveau recherche, publiés ou non, émanant des établissements d'enseignement et de recherche français ou étrangers, des laboratoires publics ou privés. 


\title{
Observations of dry particles behaviour at the tyre/road interface
}

\author{
Simon Changarnier ${ }^{\mathrm{a}, *}$, Yosra Hichri ${ }^{\mathrm{b}}$, Véronique Cerezo ${ }^{\mathrm{b}}$, Minh-Tan Do $^{\mathrm{b}}$, Ferdinando Salvatore ${ }^{\mathrm{a}}$, \\ Hassan Zahouani ${ }^{\mathrm{a}}$ \\ a Université de Lyon, ENISE, LTDS, UMRS CNRS 5513, 58 Rue Jean Parot, 42023, Saint-Etienne, France \\ ${ }^{\mathrm{b}}$ IFSTTAR, AME-EASE, 44344, Bouguenais, France
}

\section{A R T I C L E I N F O}

\section{Keywords:}

Friction

Tyre/road interface

Dry lubrication

Particles

\begin{abstract}
A B S T R A C T
Previous studies highlighted that friction value measured on real road surface textures covered by particles depends on particle sizes. This paper focuses on identification of particles behaviours at the tyre/road interface in the presence of particles. Identification is made by visual observations through high-speed camera, focus-variation microscopy and Scanning Electron Microscopy on the contaminated surface as scratch analysis on the surface. Two particle types were collected into samples picked next to roads. They are composed of clay and quartz which have different behaviours at the interface and affect the friction. Clay has a lasting effect due to its adhesive behaviour. Quartz has a scratching and rolling behaviour and is quickly ejected to the contact area due to a pinching effect.
\end{abstract}

\section{Introduction}

During a dry weather period, there is a deposit of particles (dust, debris from tyres and the road, etc.) on the road. It is widely accepted that longer is this period, more particles are gathered. All around the world further studies [1-7] have shown that most particles are mainly smaller than $125 \mu \mathrm{m}$ and concentrations of particles vary from 10 to $55 \mathrm{~g} / \mathrm{m}^{2}$.

When rainfall is starting, after a long dry period, statistics show that traffic crashes increase [8]. This is due to the accumulation of particles reducing the friction coefficient between the tyre and the road surface [9-11]. This phenomenon is called the summer ice phenomenon.

Nevertheless, Mills et al. [12] and more recently Y. Hichri et al. $[13,14]$ have observed that friction is already reduced on dry contaminated roads. These authors measured the friction by means of a Skid Resistance Tester (SRT) Pendulum which is widely used on roads field as a reference. The friction coefficient measured with this device is highly dependent on the microtexture of the surface.

Y. Hichri et al. performed a laboratory study by using a sandblasted aluminium slab covered by particles which simulates a contaminated road surface. Within the scope of their experimental design, these authors have noticed a reduced effect of the concentration of particles.
After successive friction runs, it was shown that surface covered by coarse particles (more than $80 \mu \mathrm{m}$ in size) tends to recover rapidly the clean-state friction level whereas very fine particles (less than $40 \mu \mathrm{m}$ in size) keep the friction coefficient lower than that the one of a clean surface.

The above studies are focused on macroscopic observations of friction values. To understand the variations of friction and finally propose an explanatory model, it is necessary to go deeper into involved mechanisms by making microscopic observations. Thus, previous works dealing with rail/wheel contact both in laboratory and in-situ demonstrated through Scanning Electron Microscope (SEM) observation the appearance of a film acting as a lubricant in the contact area. Depending on the size and the type of particles, several mechanisms like rolling, scratching or crushing were observed [15-19] and the characteristics and the rheological behaviour of this film evolves. The transferability of these observations to roads field is questionable due to the difference of operating conditions (speed, load, contact pressure).

The aim of this paper is to bring to light the different particles behaviours during a friction measurement in dry condition to explain their effects on the lubrication of the tyre/road contact. Firstly, particles are characterised, then the movements of particles are observed as well as the mechanical behaviour of the types of particles at the interface.

\footnotetext{
* Corresponding author.

Email address: simonchangarnier@gmail.com (S. Changarnier)
} 


\section{Materials and methods}

As explained previously, SRT pendulum was used to measure friction values. Observations of particles were performed during friction tests or after through different devices as a high-speed camera, a focus-variation microscope Alicona and a scanning electron microscope. Furthermore, several types of particles were used, two natural particles and glass spheres, to better understand mechanisms.

\subsection{Particles}

\subsubsection{Natural particles}

Natural particles are collected from two sites. The first site, named "Cheviré", is a catchment area near the Cheviré Bridge in Nantes as presented in Y. Hichri et al. [14]. The second site, named "Savenay", is a drain on a hard shoulder from the freeway linking Nantes to Saint-Nazaire (GPS coordinate: 47.363300, - 1.903233). Sediments are extracted from sites then dried and sieved in the laboratory. The protocol is described in Y. Hichri et al. [14]. It is assumed that the collected particles are equivalent to those present on roads.

Granulometries were determined by Inductively Coupled Plasma Optical Emission Spectrometry (ICP-OES).

Chemical elements were determined by NF EN 12880, NF EN 18879 , NF X31-147, NF EN ISO 11885 and an internal method of alkaline molten.

\subsubsection{Glass spheres}

Standardised glass spheres (NF EN 13036-1) of $180-250 \mu \mathrm{m}$ in diameter are employed to compare their behaviours to natural particles ones, through the high-speed camera. It was necessary to employ relatively big model particles. Indeed, natural particles are too small to view their behaviour through the high-speed camera. Furthermore, natural particles are composed of particles of different nature and it is complicated to identify them and to distinguish their behaviours. Lastly, as glass spheres are chemically inert, it is possible to assess only to mechanical behaviours of particles without chemical interactions.

To identify glass sphere behaviours, as it was difficult to distinguish one sphere from another with a random spreading, it was decided to put one sphere by centimetre square in area of the slab surface. This unit $\left(1 \mathrm{~cm}^{2}\right)$ is chosen because it represents the area of one aggregate.

As spheres being small, it is tough to drop one sphere off every centimetre square, the best way found to spread spheres regularly is to use a sieve having meshes of $165 \mu \mathrm{m}$ in which holes were enlarged at a regular distance thanks to a standardised penetration needle (NF EN 1426). When glass spheres are spread on the holed sieve, only one sphere by hole is dropped off on the slab placed underneath the sieve.

\subsection{Test protocol}

\subsubsection{Friction measurement}

The same testing procedure as the one of Y. Hichri et al. [14] was followed. Friction was measured on a clean and dry aluminium slab, as indeed Y. Hichri et al. [13] showed, roughness parameters of the aluminium slab are similar to road aggregates polished by the traffic. The friction was measured after the deposit of particles, then the measurement of friction was repeated until stabilisation of the friction coefficient. Different fractions of particles $(0-40,40-50,50-80,80-100$ and $0-100 \mu \mathrm{m})$ and concentration $\left(10,20\right.$ and $\left.40 \mathrm{~g} / \mathrm{m}^{2}\right)$ were tested with natural particles.

The friction slider of the SRT pendulum is made of rubber and rubs a sandblasted aluminium slab being 130 by $80 \mathrm{~mm}$. The friction slider represents a tread block of a tyre. The sandblasted aluminium slab has a microtexture similar to polished aggregate. As microtexture is one main parameter having an impact on friction, it is essential to use a representative surface [20].

During friction tests, carbon adhesive discs were placed after the aluminium slab to collect ejected particles and a high-speed camera recorded the passes of the rubber slider (Fig. 1).

\subsubsection{Material for observations of particles behaviours}

2.2.2.1. High-speed camera During friction measurement, the passage of the rubber over the slab was recorded by means of a high-speed camera. This enables to view particle movements. The body of the camera is a Motion BLITZ Cube 4 and the lens is a Sigma $105 \mathrm{~mm} \mathrm{1:2,8}$ DG MACRO. It was necessary to light up as much as possible the subject matter to take distinct pictures of particles. Parameters were optimised as follows to have the clearest pictures:

- Frame rate: 6000 frames/s

- Shutter time: $100 \mu \mathrm{s}$

- Frame geometry: 1280 by 171 pixels

- Lens aperture: $\mathrm{f}-2.8$

- Zoom lens: 1:1

The size of a pixel announced by the camera builder is $12 \mu \mathrm{m} \times 12 \mu \mathrm{m}$. It was confirmed by measuring the number of pixels of a picture between graduations of a precise ruler. Count of pixels is made through the free software GNU Image Manipulation Program. This enables to measure the distance travelled by particles and their velocity knowing the time slot between two frames. The high-speed camera is placed in such a way that it records the centre of the slab at $5 \mathrm{~mm}$ from the edge, as shown in Fig. 1. The limit of this camera is the depth of field which is limited to approximately $1.5 \mathrm{~mm}$.

2.2.2.2. Focus-yariation microscope During friction tests, carbon adhesive discs were placed $50 \mathrm{~mm}$ away from the slab to capture particles ejected from it at passages $1,2,3,5$ and 12. In accordance with Y. Hichri et al. [13], the passages 1,2 and 3 correspond with the fastest variation of the friction. Passage 5 corresponds with the slow increase of the friction and it is the passage at the half of the test. Passage 12 corresponds with the stabilisation of the friction coefficient. That distance of $50 \mathrm{~mm}$ was chosen after tries which showed that it is the best place to catch a maximum of particles. After each passage of the slider, a new disc was placed. These carbon adhesive discs were studied at the focus-variation microscope Alicona to see the evolution of ejected particles over passing.

Thanks to many lenses of the focus-variation microscope, it is possible to have an overview of particles ejected as well as details of particles of a few nanometres. The limit of the focus-variation microscope of the laboratory is that it only gives a 3D view from above, thereby it is not optimal to use the focus-variation microscope to see particles on the sandblasted aluminium.

2.2.2.3. Scanning electron microscope The Scanning Electron Microscope aims at having more details on particles and their distribution on the surface of the aluminium slab as well as their chemical composition. The limit of the SEM is the time needed to analyse samples. The time to observe all samples of the design of experiments and the slab at every step and with both particles was immoderate. Thus, only some samples were analysed with the SEM.

\subsection{Strategy}

The strategy of the investigation was to characterise both natural particles (I), then the movement of particles is determined and compared to the one of glass spheres (II), afterwards carbon adhesive discs are observed through the focus-variation microscope to determine the order of ejection of different particles (III). Finally, observations 

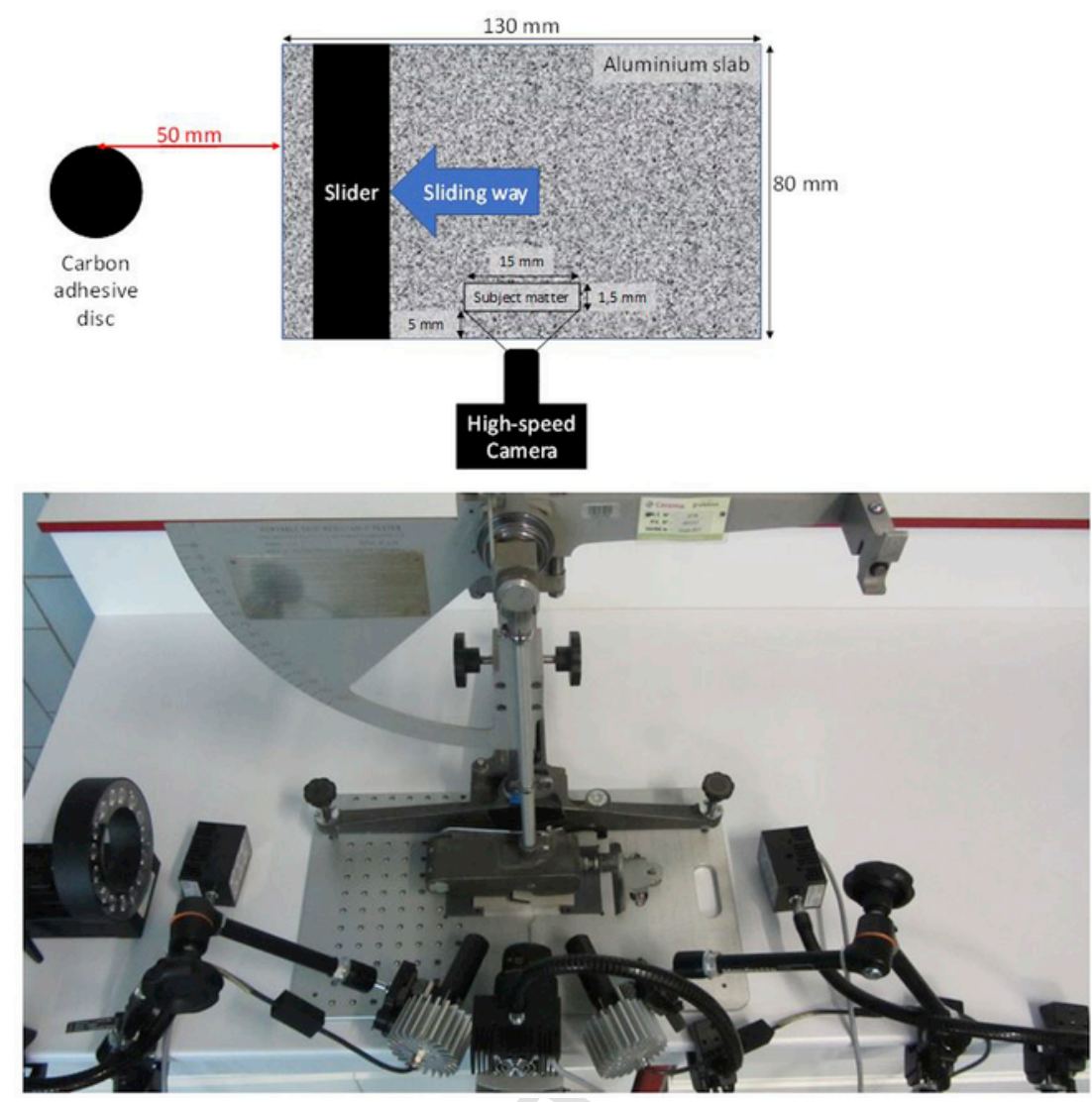

Fig. 1. Test rig.

through the SEM and the Alicona are employed to understand particles behaviours at the interface (IV).

\section{Theory}

First of all, Mills et al. [12], H. Heshmat [19] or K. Li et al. [21] found that dry particles can entail a decrease of friction values by acting as a lubricant in the contact area. They highlighted the role of particles size which generates various mechanical behaviours.

Thus, Mills et al. stated that a critical size of particles lying between 50 and $60 \mu \mathrm{m}$ exists to switch from one behaviour to another. Above this threshold, particles tend to roll when a rubber pad sweeps the surface whereas under this limit particles tend to stick together due to cohesive forces and promote a sliding mechanism at the rubber slider/surface interface. When the particles are very hard, they tend to scratch the surface of the rubber. These grooves are few micrometers wide and observable only with accurate microscopes.

Moreover, Mills et al. established that the surface roughness plays a role in friction generation at the interface as particles can be trapped by the surface texture. Thus, some particles cannot go over surface asperities, which contributes to the shearing of particles layers.

Heshmat [22] on his side found that solid particles (i.e. powder) can form a lubricant film which exhibits similar characteristics than a fluid. This result is true only for a certain range of particles size (around $5-20 \mu \mathrm{m}$ ). This film can be considered as a third body which plays a role in the friction between the rubber pad and the pavement surface.

Lastly, Y. Hichri et al. $[13,14]$ demonstrated that the finest fraction (i.e. $0-40 \mu \mathrm{m}$ induces a lower friction value after one measure with particles (step 1), then the increase of the friction value with the number of steps is the slowest. Friction values measured with the fraction
$80-100 \mu \mathrm{m}$ increase rapidly after step 1 . Based on these observations, Y. Hichri et al. assumed that big particles are ejected from the first passes of the rubber slider without being blocked by the surface texture, whereas small particles tend to stick on the surface and need more passes to shear the particles layers. Additionally, Y. Hichri et al. observed that it was not possible to recover the initial level of friction (i.e. on clean surface) which confirms that some particles should stay at the interface creating a film of lubricant. Validation of these assumptions are expected through deep analysis of the state of contamination of the surface during and after friction measurements.

\section{Results and discussion}

\subsection{Characterisation of natural particles}

Fig. 2 displays granulometries by fractions of particles from the two sites. Graduations on the outer diameter are particle sizes and graduations on inner diameters are percentages of presence of the size of particles into a fraction. As an example, the fraction $40-50 \mu \mathrm{m}$ from Savenay is composed of $25 \%$ of $40 \mu \mathrm{m}$ particles. All the same fractions are similar for both origin except for fraction $50-80 \mu \mathrm{m}$. An explanation will be given later.

Chemical elements analyses (Fig. 3) show that all fractions are composed of around $68 \%$ of $\mathrm{Si}, 12 \%$ of $\mathrm{Al}, 6 \%$ of $\mathrm{Fe}, 3.5 \%$ of $\mathrm{Na}, 3.7 \%$ of $\mathrm{Ca}, 4 \%$ of $\mathrm{K}, 1.5 \%$ of $\mathrm{Mg}, 0.57 \%$ of $\mathrm{Ti}$ and other elements are in insignificant amounts. By this analysis particles from the two picking areas could be considered as similar from a chemical point of view. Thanks to the high percentage of silicon and the rather significant quantity of aluminium, it can be assumed that particles samples are made up of quartz ( $\mathrm{SiO} 2)$ and clay $(\mathrm{SiO} 2+\mathrm{Al} 2 \mathrm{O} 3)$. Those two materials have opposite mechanic behaviours. Quartz has a Vickers hardness 

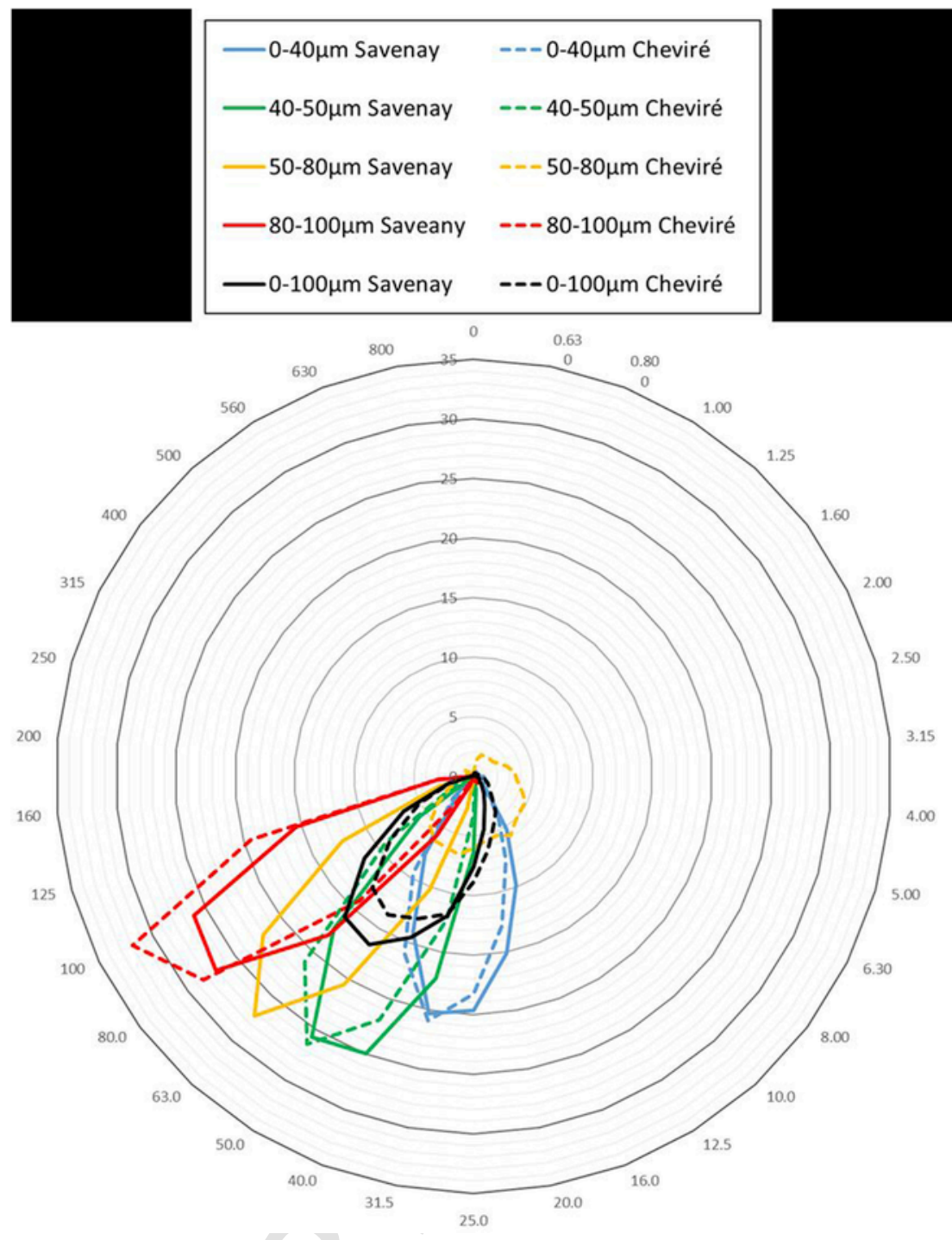

Fig. 2. Granulometry of natural particles.

of $100 \mathrm{MPa}$ while clay is totally soft. A low normal stress directly causes internal shearing.

To support this hypothesis some observation with the focus-variation microscope and the SEM are made. First particles of fraction 0-100 $\mu \mathrm{m}$ of Savenay and Cheviré deposited on a white sheet of paper were observed through the focus-variation microscope. To highlight the clay behaviour untouched and crushed samples were observed (Fig. 4).

Particles from Savenay are mainly unaltered while particles from Cheviré are crumbled. It can be noticed that black particles are crumbled and white ones are intact. Thus, it could be considered that black particles are clay and white ones are made up of quartz. The chemical composition of particles of quartz and clay are similar, but as the observation by focus-variation microscope show, the mineralogy is different.

On pictures of the fraction $0-100 \mu \mathrm{m}$ from Cheviré it can be noticed that the major part of particles larger than $50 \mu \mathrm{m}$ are made up of clay. In Fig. 4, the fraction $50-80 \mu \mathrm{m}$ from Cheviré shows an unexpected granulometry. From now onwards, it is assumed that the fraction $50-80 \mu \mathrm{m}$ has been compressed and agglomerates of clay were crumbled during manipulations. The fraction $40-50 \mu \mathrm{m}$ from Cheviré is mainly made up of quartz. Thus, the fraction $0-100 \mu \mathrm{m}$ from Cheviré is principally made up of quartz from the fraction $40-50 \mu \mathrm{m}$ and clay from fraction $50-80 \mu \mathrm{m}$.

To picture more easily particles behaviours, some images are taken by the SEM. Particles from Chevire are used to picture the behaviour of clay (Fig. 5). On the left, there is a particle of quartz with some small particles of clay stuck on them. On the right, there is an agglomeration of clay.

Two main particles occur in the contact and have different behaviours. To view their movements, we used samples from Savenay because they do not crumble and it is easier to see them with the high-speed camera ( 1 pixel is 12 by $12 \mu \mathrm{m}$ ). To observe them at the interface by the SEM, we used particles from Cheviré.

\subsection{Friction values}

To validate the following observations, it is necessary to ensure that friction values are similar to Y. Hichri et al. [14] ones. According to the standard NF EN 13036-4, friction values are judged similar if the difference is below 0.05. As it is shown in Fig. 6 friction values for 10 and $40 \mathrm{~g} / \mathrm{m}^{2}$ of the fractions $0-100 \mu \mathrm{m}$ from Cheviré measured by Y. Hichri et al. [14] and in this study are equal, which validates the following observations. Nevertheless the friction values of particles from Savenay 


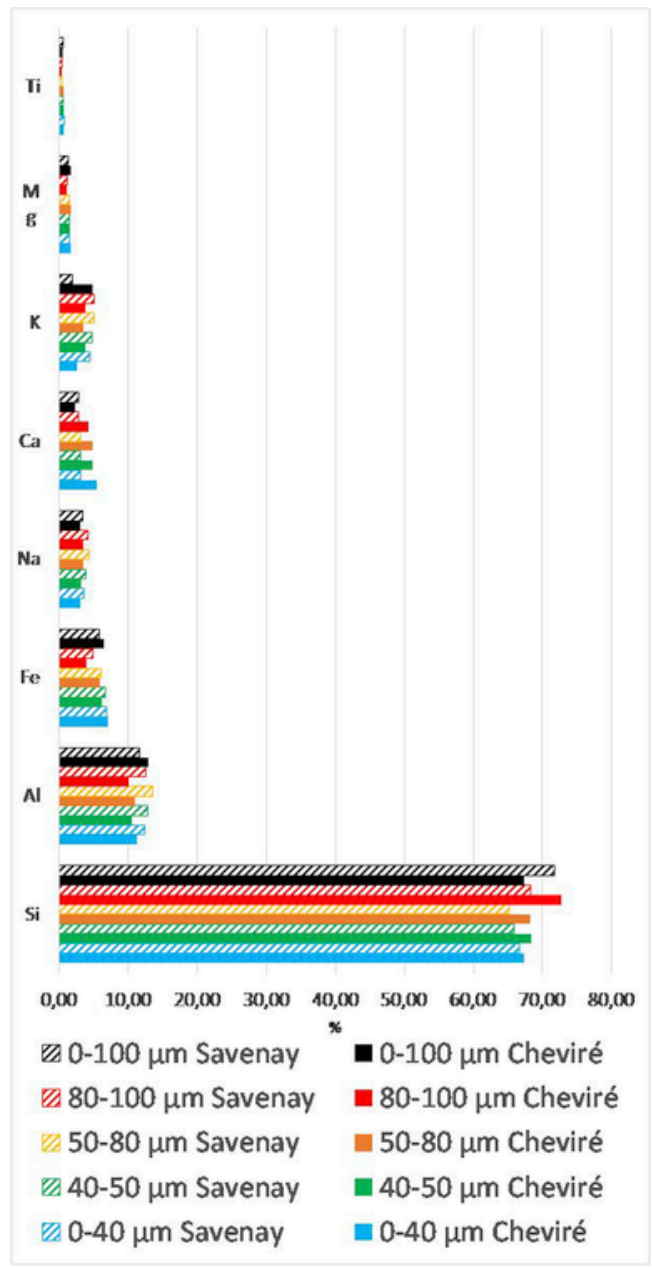

Fig. 3. Main chemical elements of natural particles.

are higher than the ones of particles from Cheviré. As shown previously particles from Cheviré and Savenay are different and might not have the same behaviour.

\subsection{Movement of particles}

Movements of particles are seen through the high-speed camera recording passages of friction slider on the sandblasted aluminium slab covered by $10 \mathrm{~g} / \mathrm{m}^{2}$ of particles from Savenay. This section presents results obtained with the fraction $0-100 \mu \mathrm{m}$ which is the most representative of particles present on the road.

\subsubsection{Overall movement}

Series of MEB analysis show the diminution of the quantity of particles on the surface at every passage. Indeed at the first passage on the aluminium slab is covered with particles and after each passage it is possible to see more and more aluminium and fewer particles. This observation shows that the slider passes on different layers of particles. High-speed camera records show that particles are ejected and form a cloud of particles following the slider. The fact that they are not pushed towards the front is attributed to the microtexture of the surface of the slab which traps the particles. To verify this hypothesis, which was already highlighted by R. Mills et al. [12] and Y. Hichri et al. [14], an extra test was made on a smooth aluminium slab and it shows that particles are actually pushed by the slider.

The cloud following the friction slider is composed of particles and fragments of rubber of the slider. The slider is worn out by the microtexture of the slab. Indeed, the more passages are carried out, more particles from Savenay are ejected and the more fragments of the slider appear.

The cloud is generated by two phenomena. On the one hand, the depression caused by the movement of the SRT pendulum which sucks particles up a few millimetres behind the slider. On the other hand, some particles are ejected at the rear of the slider and leave the surface in the opposite direction of the slider with a speed around $0.8 \mathrm{~m} / \mathrm{s}$ in our case. Once aloft, particles change of direction due to air flow and follow the slider displacement. Finally, particles settle bouncing on or next to the aluminium slab.

To clear up the mechanism of ejection of particles, observation of glass spheres of $200 \mu \mathrm{m}$ in diameter is made (Fig. 7). The same ejection process appears. The sphere goes under the slider and is ejected at the rear. The difference lies in the speed of glass spheres which is around $3.4 \mathrm{~m} / \mathrm{s}$, and that the trajectory doesn't deviate due to air flow. This can be explained by the kinetic energy of the sphere which is higher as glass particles are heavier and go faster than natural particles.

As quartz, glass spheres and aluminium are harder than the rubber of the slider. The slider is the most deformed and saves deformation energy when a particle goes between the slider and the slab. When the surface texture blocks the particle at the interface, the slider is deformed. Then the slider slides rubbing the particle until the edge of the slider. Just as the particles go out of the interface the rubber gets back

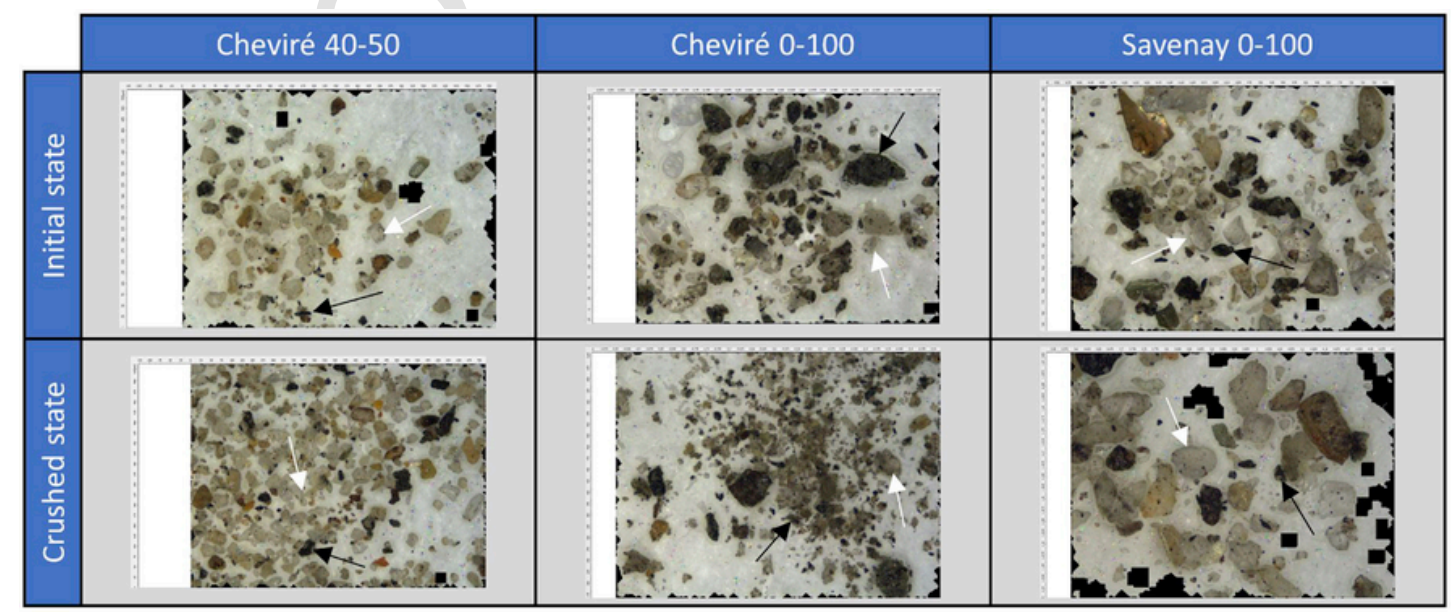

Fig. 4. Particles from Chevire \& Savenay; Black arrows indicate particles of clay; white arrows indicate particles of quartz ( $\times 20$ magnification, Alicona). 


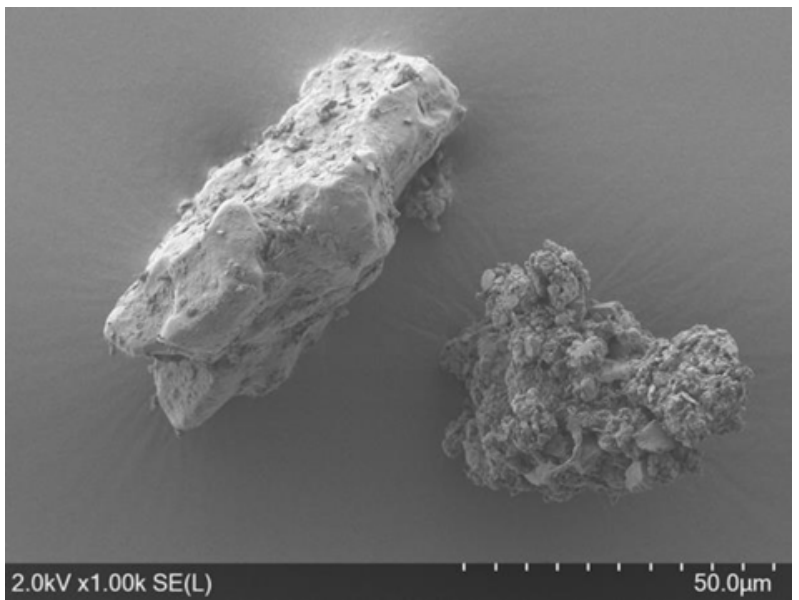

Fig. 5. Quartz particle on the left and clay aggregate on the right (SEM).

its initial geometry and there is a pinching effect throwing out the particles.

As seen through high-speed camera, the larger is a particle, the more energy of deformation is accumulated into the rubber and more energy is given by a pinching effect to particles to leave the aluminium slab.

In the case of particles from Savenay, particles fly away and then are blown away by the airflow. Thus, the larger particles are, the higher they go and further away they settle.

\subsubsection{Ejection order}

To confirm the reasoning just suggested, adhesive carbon discs were observed after 1, 2, 3, 5 and 12 passages of the friction slider. These passages are chosen in connection with the variation of friction values. Indeed, between passage 5 and the stabilisation at passage 12, friction values increase slowly and regularly. Particles from Savenay are used in the same concentration and fraction as for tests done with the high-speed camera.

Before analysing pictures in Figs. 8 and 9 (obtained by means of the focus-variation microscope), it is important to specify that there are optical effects on them. Discs are black, but with the high intensity of light of the measuring sensor, there is a reflection in the adhesive, thus, discs look white. In the same way, quartz is translucent, and some particles look black due to the colour of the disc underneath.

Fig. 8 presented pictures taken at $10 \times$ magnification. The quantity of particles ejected decreases as the number of passages increases. As expected, largest particles are found on the disc after the first passage and to a lesser extent on the second disc corresponding to the second passage. Then the size of most of particles is stable around $50 \mu \mathrm{m}$.

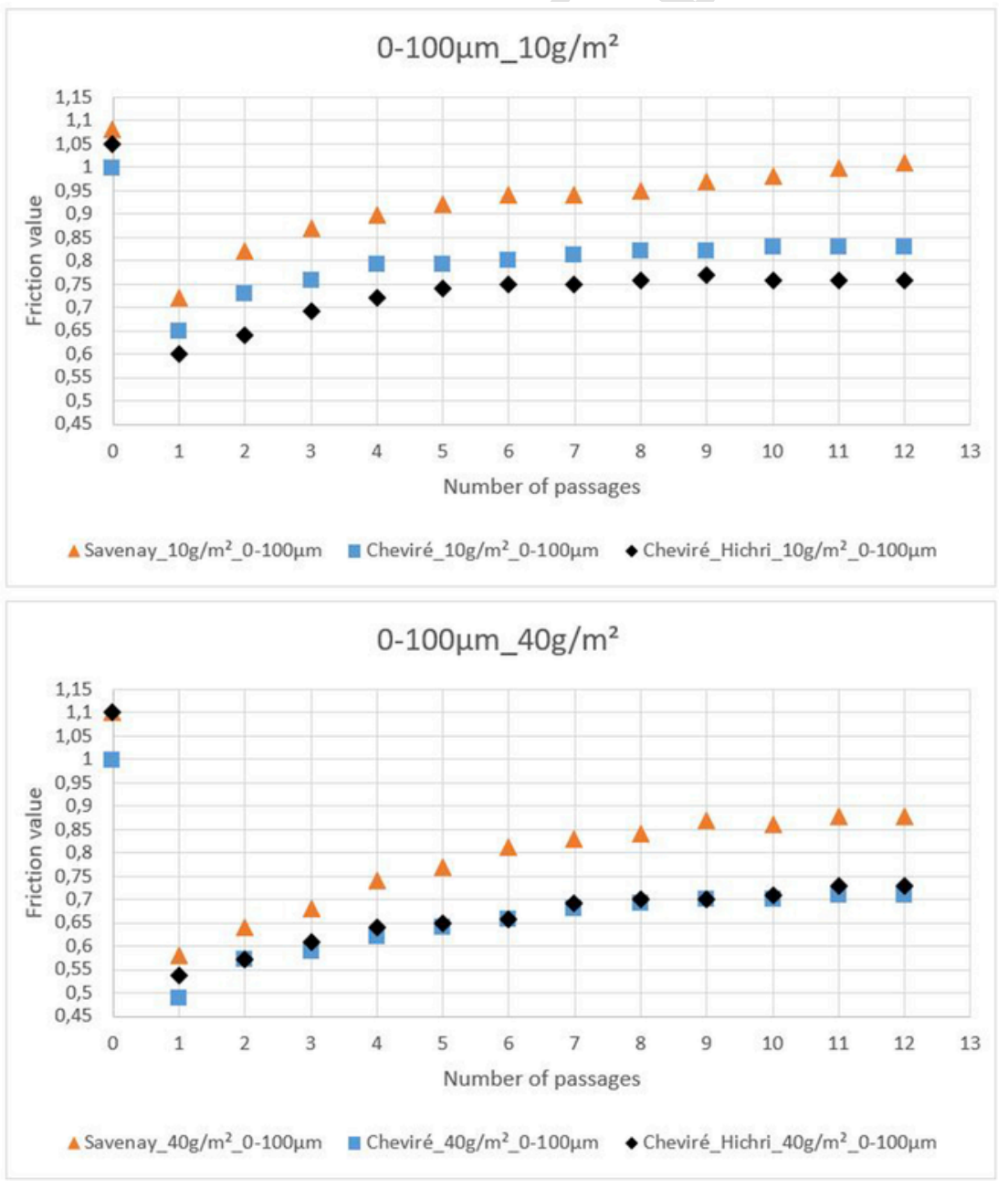

Fig. 6. Friction values. 


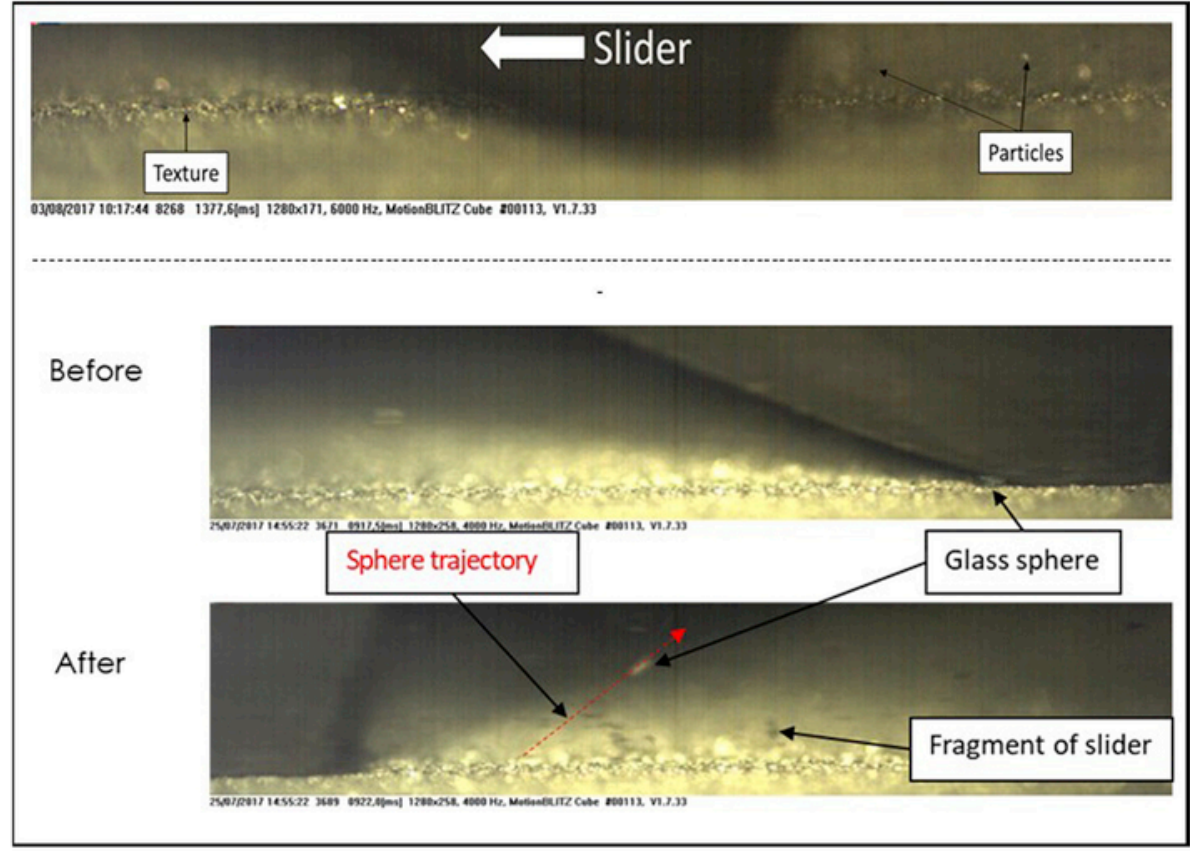

Fig. 7. Upper figure: first passage of the slider on $10 \mathrm{~g} / \mathrm{m}^{2}$ particles of fraction $0-100 \mu \mathrm{m}$ from Savenay; lower figure: glass sphere (High-Speed Camera).

It is also interesting to have a look at the nature of the ejected particles. To illustrate the upcoming analysis, Fig. 9 shows, at $\times 20$ magnification, ejected particles at passage 1, 5 and 12. Three types of particles are observed on discs. There are quartz particles which are mainly ejected during first passages. Then there are clay particles which are ejected quite in the same proportion. Finally, there are rubber fragments which appear more and more over passages and the microtexture of the sandblasted slab is uncovered. Typically, in Fig. 9, at passage 12, on the top right-hand corner, the small agglomerates in the shape of a crescent moon is a rubber fragment.

Thus, it is seen that larger particles are ejected first and the amount of ejected quartz particles reduce with the number of passages, while the ejected quantity of clay is stable. To explain this phenomenon, it is necessary to go into more mechanical behaviour of particles at the interface in depth.

\subsubsection{Comparison with aggregates taken off the road}

To compare the previous observations to real contamination on the road, two aggregates were taken off the road on the test site of Savenay after 10 days of dry weather. The first aggregate was taken off the hard shoulder and the second one from the right wheel path (worn part of a road). These two aggregates were observed through SEM (Fig. 10). The aggregate from the hard shoulder has, on its surface, particles of quartz (up to $100 \mu \mathrm{m}$ ) and agglomerates of clay. Indeed, chemical analysis by the SEM shows that particles are mainly made up of $\mathrm{SiO}_{2}$. Unlike the aggregate from the wheel path which has some tiny particles $(<10 \mu \mathrm{m})$ of quartz and clay. Furthermore, there are many deposits of contaminants which do not seem to be minerals because of cracking and their chemical compositions (see Table 1, please note that these chemical analyses cannot be considered as any evidence due to lack of data, but the authors want to indicate deeper investigations to undertake).

These observations tend to confirm that quartz particles larger than $50 \mu \mathrm{m}$ are ejected from the surface.

\subsection{Mechanical behaviour of particles at the interface}

Observing mechanical behaviour (rolling, scratching, sticking) of particles at the interface is almost impossible with our materials. However, it is possible to observe tracks of particles.

Particles can show three behaviours on: rolling, scratching or sticking. Quartz particles can roll and scratch. Clay particles can roll, scratch and stick.

\subsubsection{Quartz behaviour}

At the interface quartz might adopt rolling or scratching behaviour, because it is an inert material. It is also the hardest material at the interface, thus it may scratch the rubber of the slider and the aluminium slab. It is not wise to observe scratches on the rubber because it is the softer material and scratches could also come from the contact with the sandblasted aluminium slab. Consequently, scratches are searched on the slab through the focus-variation microscope.

Scratches were found (Fig. 11) on peaks and valleys. Most of them are orientated in the sliding direction and this confirms that wear is the cause of them. So, quartz has a scratching behaviour.

The rolling behaviour of the quartz is not observable with our material. We can only assume that at the interface that quartz particles can also roll thanks to the different of pressures of contact due to the "topography" of the aluminium slab.

Several topographic measurements were made for a quantitative analysis of the contact parameters. From the plastic contact theory, we can define the following parameters [23-25].

The half width of the scratch or radius of contact $a_{p}(\mu \mathrm{m})$ is measured on the aluminium slab and enables to calculate the plastic contact area $A_{p}$ of a particle presumed spherical:

$A_{p}=\pi a_{p}^{2}$ 

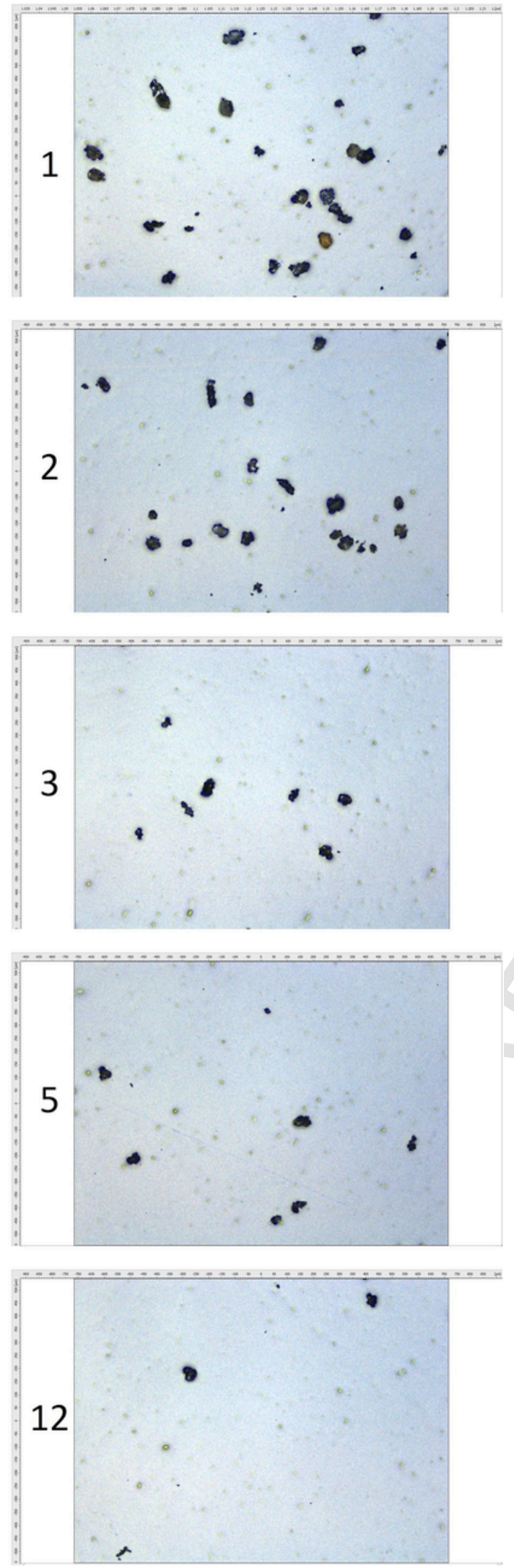

Fig. 8. Ejected particles by passages ( $\times 10$ magnification, Alicona).
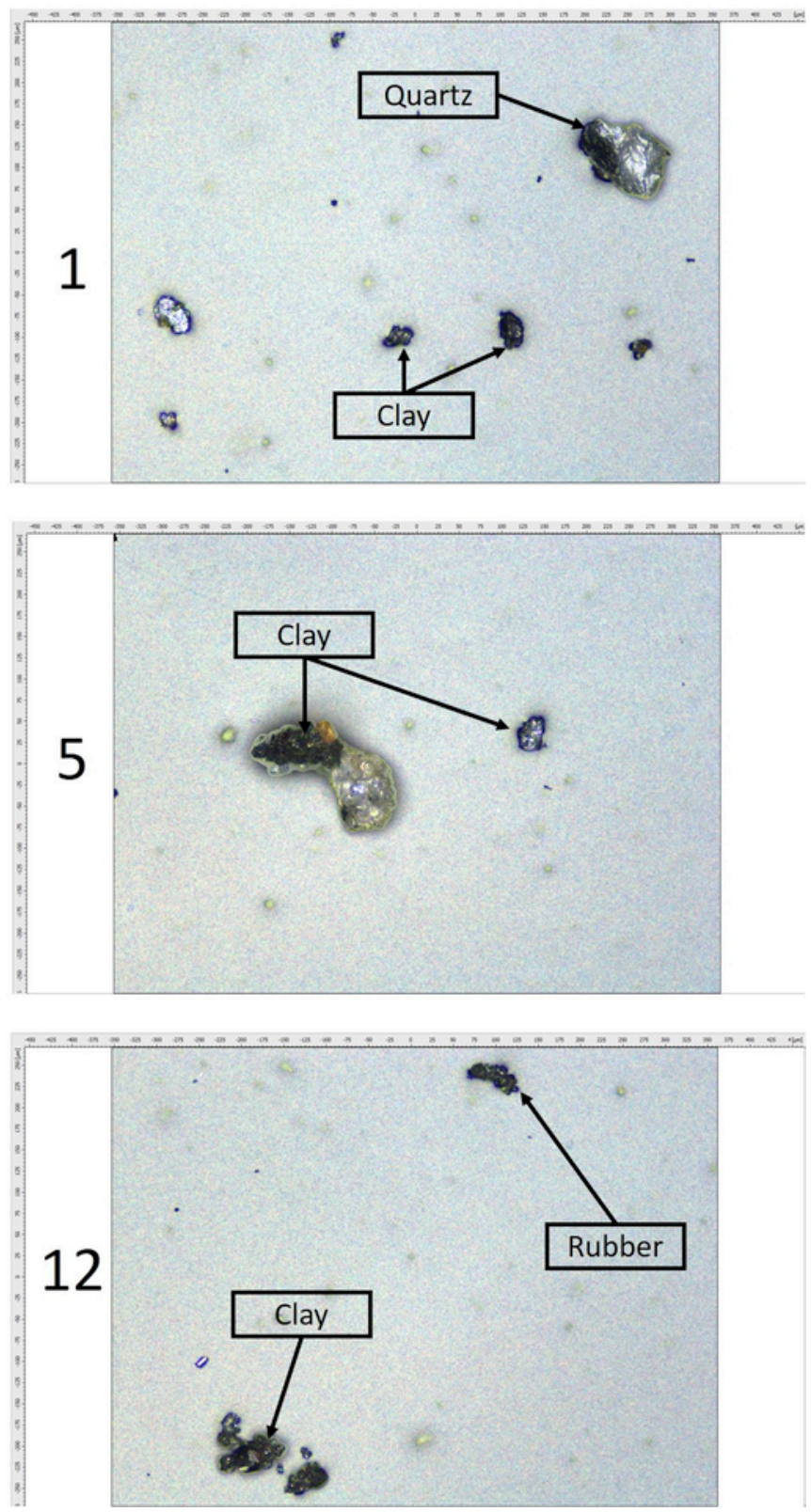

Fig. 9. Ejected particles by passages ( $\times 20$ magnification, Alicona).

The plastic contact area of an asperity is defined by Abbott and Firestone [26] as:

$A_{p}=\pi R^{2}\left(\frac{2 R \delta}{R^{2}}-\frac{\delta^{2}}{R^{2}}\right)$

With $\mathrm{R}$ the radius of the particle and $\delta(\mu \mathrm{m})$ the depth of the scratch (Fig. 12).

Thus the relationship between the half width of the scratch (contact radius) and the radius of the particle that caused the scratch can be written as:

$a_{p}=\sqrt{2 R \delta-\delta^{2}}$

This relationship made it possible to determine the radius of the different particles on six topographic measurements of the scratches. 

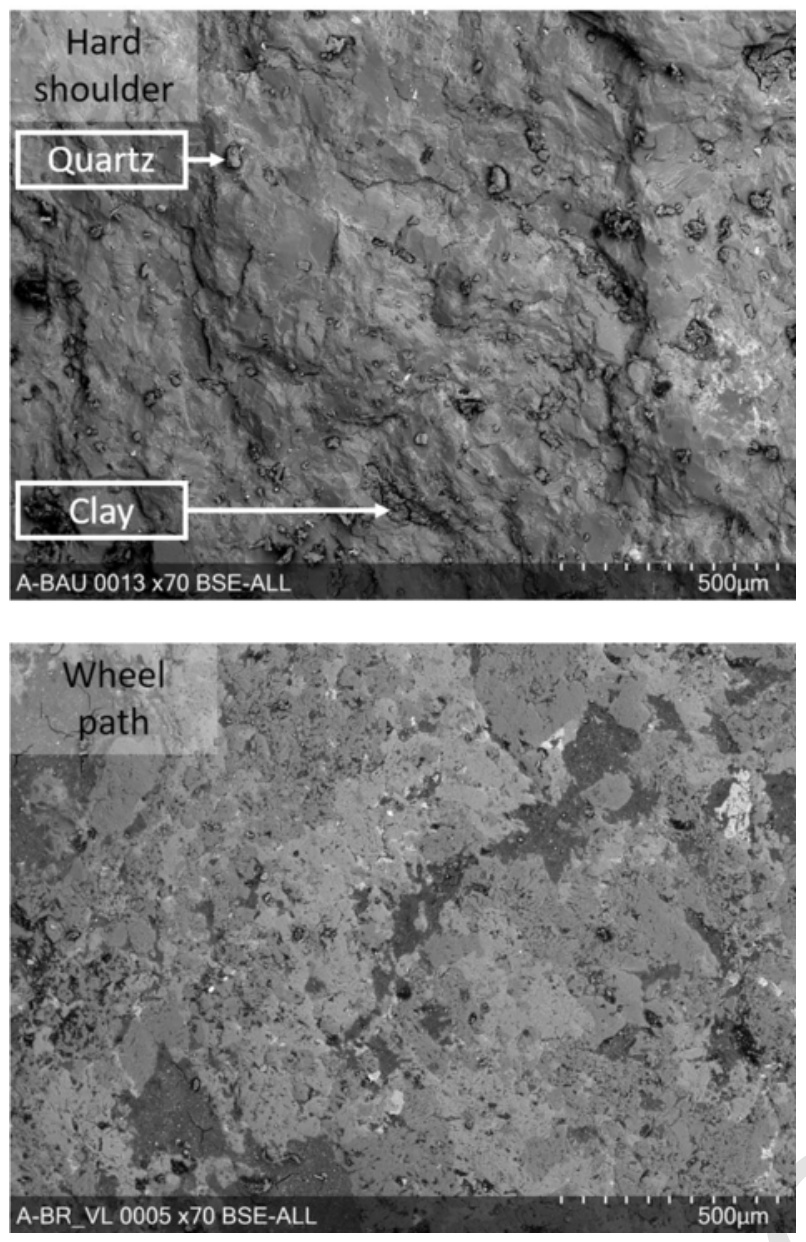

Fig. 10. Observation of two different aggregates from Savenay (SEM).

Three other parameters were quantified from the knowledge of the radius of the particle and the radius of contact:

The degree of penetration is defined as $: D_{p}$

$=0.42 \delta a_{p}$

The local plastic force : $F_{p}(N)$

$=\pi a_{p}^{2} H(\mathrm{H}$ is the hardness of aluminium)

The coefficient of friction of deformation : $\mu_{\text {Def }}$

$$
\begin{aligned}
& =\frac{H A_{t}}{H A_{n}} \\
& =\frac{4}{3 \pi} \frac{a_{p}}{R}
\end{aligned}
$$

The entire calculation is presented in Table 2. It may be noted that the particles whose radius of curvature is greater than $25 \mu \mathrm{m}$, cause a low degree of penetration ( $D_{p}<3 \%$ ), a low scratching force and a low coefficient of friction of deformation. On the other hand, particles with a radius of curvature lower than $25 \mu \mathrm{m}$, cause high degrees of penetration ( $D_{p}>5 \%$ ), with a high coefficient of friction of deformation.

About particles of quartz, it is finally observed that they are ejected from the surface due to a pinching effect caused by the deformation of the rubber of the slider on a particle stuck on a rough patch.

This pinching effect explains why on the aggregates (taken in the right wheel path) we did not observe particles bigger than $10 \mu \mathrm{m}$. In the literature particles are picked on the road thanks to vacuum cleaners. This method is questionable as much as the one presented in this paper, because they catch ejected particles and particles located into hollows between aggregates. Indeed, thanks to the high-speed camera it was observed that particles could be sucked up by the air flow, therefore they could be caught by the vacuum cleaner as much as they could settle on the hard shoulder (and on the road where they will be quickly ejected by the pinching effect and go to the hard shoulder and to the drain). Some quartz particles can deposit on the wind thanks to the wind, trucks loaded of rubble, tractors, the wear of the road infrastructure, and so on. At the same time quartz particles on the wheel path are ejected by the traffic and the pinching effect. Thus the quantity of large particles of quartz on the road must be quite stable and quite low.

\subsubsection{Clay behaviour}

Clay is a material having no resistance to normal stress [27]. Therefore, while the slider rubs the surface, agglomerates of clay might break up and stick to the aluminium slab.

To visualise the adhesion of the clay in the contact area, some analyses with SEM are made after different numbers of passes of the slider (Fig. 13). $40 \mathrm{~g} / \mathrm{m}^{2}$ of the fraction $0-100 \mu \mathrm{m}$ of particles from Chevire are used because they contain more clay than the ones from Savenay. To analyse the behaviour of clay particles, pictures taken through SEM are compared to pictures taken with the fraction $40-50 \mu \mathrm{m}$ from Cheviré, because these particles are more made up of quartz than the first one. The same concentration was also used. Both fractions have the same origin, thus, quartz contained in the fraction $0-100 \mu \mathrm{m}$ and the one of the fraction $40-50 \mu \mathrm{m}$ have the same behaviour.

After one passage, the difference is clear, quartz particles are in valleys, while clay is all over the surface. Friction values are stable after 12 passages for the fraction $0-100 \mu \mathrm{m}$ and 11 for the fraction $40-50 \mu \mathrm{m}$. It is also clear that particles of quartz are ejected, or into valleys, and particles of clay are all over, even on peaks.

Thus, it is shown that clay has an adhesive behaviour in addition to limited (but probable) behaviour of rolling and scratching because clay could be mixed with quartz fragments.

\subsection{Relationship between particles behaviour and friction}

As explained in the introduction, several authors have shown that friction values depend on the size of particles. More specifically Y. Hichri et al. $[13,14]$ noticed that the presence of particles smaller than $40 \mu \mathrm{m}$ has a huge and lasting influence on friction. They measured a

Table 1

\begin{tabular}{|c|c|c|c|c|c|c|c|c|c|c|}
\hline & $\mathrm{Na} 2 \mathrm{O}$ & $\mathrm{SiO} 2$ & $\mathrm{SO} 3$ & $\mathrm{~K} 2 \mathrm{O}$ & $\mathrm{CaO}$ & $\mathrm{Al} 2 \mathrm{O} 3$ & $\mathrm{MgO}$ & $\mathrm{FeO}$ & $\mathrm{P} 2 \mathrm{O} 5$ & $\mathrm{TiO} 2$ \\
\hline Black contaminant & 3.4 & 46.9 & 10.2 & 3.5 & 7.3 & 16.4 & 2.7 & 7.8 & 3.7 & 3.0 \\
\hline White contaminant & 0.3 & 1.6 & 0.7 & 0.1 & 58.8 & 0.4 & 0.1 & 0.1 & 37.9 & 0.0 \\
\hline
\end{tabular}

Compositions of contaminants. 


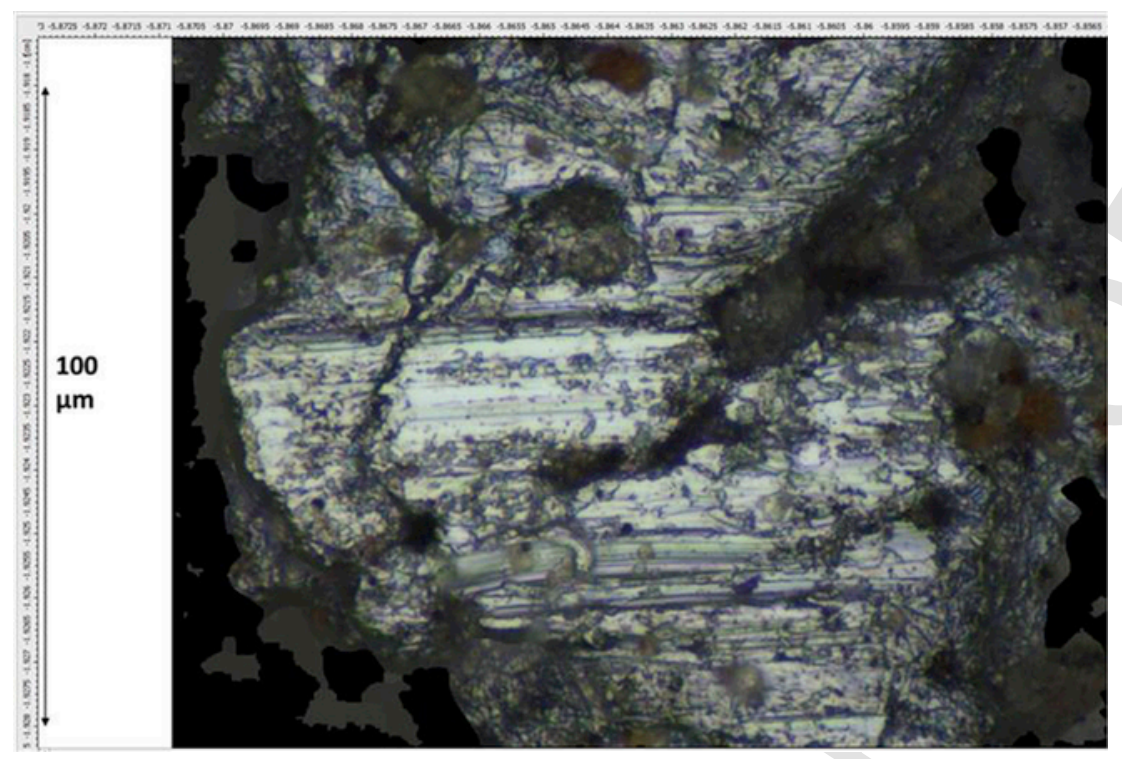

Fig. 11. Scratches on aluminium ( $\times 100$ magnification, Alicona).

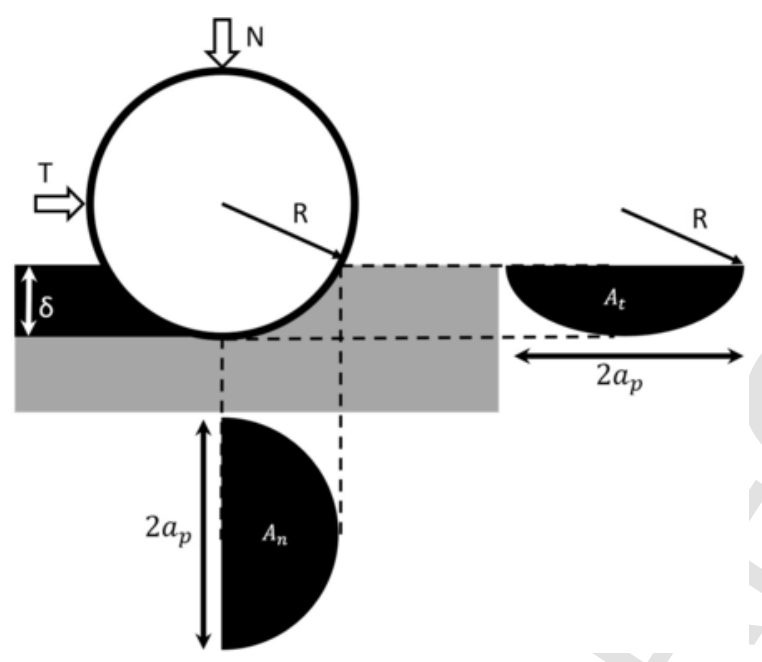

Fig. 12. Plastic deformation and wear theory.

lower friction coefficient for the first passage with the fraction $80-100 \mu \mathrm{m}$ than with the fraction $0-40 \mu \mathrm{m}$. Scratches analysis showed that particles with a radius of curvature greater than $25 \mu \mathrm{m}$ have a lower coefficient of friction of deformation than particles with a radius lower than $25 \mu \mathrm{m}$. They also observed that in the presence of larger particles, friction values rapidly increase after the first passage. They suggested that the size of particles is linked to the friction by the texture of the aluminium slab and its capacity to retain particles.

This hypothesis is still valid. However, now it is known that friction value is also linked to the nature of particles. Indeed, when clay is stressed, agglomerates are crumbled in small particles which stick to the surface and fill valleys reducing micro-indentation and friction. As for large particles which are quickly ejected, this is because they are made up of quartz and deform the rubber of the slider before being ejected by the pinching effect. That happens thanks to the microtexture blocking particles of quartz. These new evidences allow to explain the difference of friction values between the tests with particles from Cheviré and Savenay exposed in Fig. 6. Indeed particles from Savenay are more made up of quartz they contain less clay than particles from Cheviré. Thereby particles of quartz are ejected faster while the clay is crumbled and stays on the aluminium slab. Therefore the friction values of the particles from Chevire are lower than the friction values of the particles from Savenay.

\section{Conclusion and perspectives}

In this paper, the behaviour of particles in the tyre/road contact area was studied experimentally and observed through a high-speed camera, a focus-variation microscope and a Scanning Electron Microscope.

Particles were collected from reservoirs of runoff water (catchment area or road drain) next to trafficked roads. They are mainly made up of quartz and clay which show different behaviour at the tyre/road interface. Quartz has a rolling and scratching behaviour and wears the surface. Some simplified calculus indicated that particles whose radius of curvature is greater than $25 \mu \mathrm{m}$, cause a low degree of penetration $\left(D_{p}<3 \%\right)$, a low scratching force and a low coefficient of friction of deformation, whereas particles whose radius of curvature is lower than $25 \mu \mathrm{m}$, cause high degrees of penetration ( $D_{p}>5 \%$ ), with a high coefficient of friction of deformation.

Table 2

Quantitative analysis of contact parameters through the morphology of abrasive scratches.

\begin{tabular}{|c|c|c|c|c|c|c|}
\hline & $a_{p}(\mu \mathrm{m})$ & $\delta(\mu \mathrm{m})$ & $\mathrm{R}(\mu \mathrm{m})$ & $D_{p}(\%)$ & $\boldsymbol{F}_{p}\left(10^{-3}\right) \boldsymbol{N}$ & $\mu_{D e f}$ \\
\hline 1 & 3.00 & 0.1 & 45 & 0.014 & 4.80 & 0.028 \\
\hline 2 & 3.24 & 0.2 & 26.4 & 0.026 & 5.62 & 0.052 \\
\hline 3 & 4.99 & 0.3 & 41.66 & 0.025 & 12.29 & 0.051 \\
\hline 4 & 14.20 & 14 & 14.2 & 0.414 & 107.61 & 0.425 \\
\hline 5 & 8.77 & 2 & 20.25 & 0.096 & 41.10 & 0.184 \\
\hline 6 & 14.36 & 10 & 15.31 & 0.292 & 110.07 & 0.398 \\
\hline
\end{tabular}



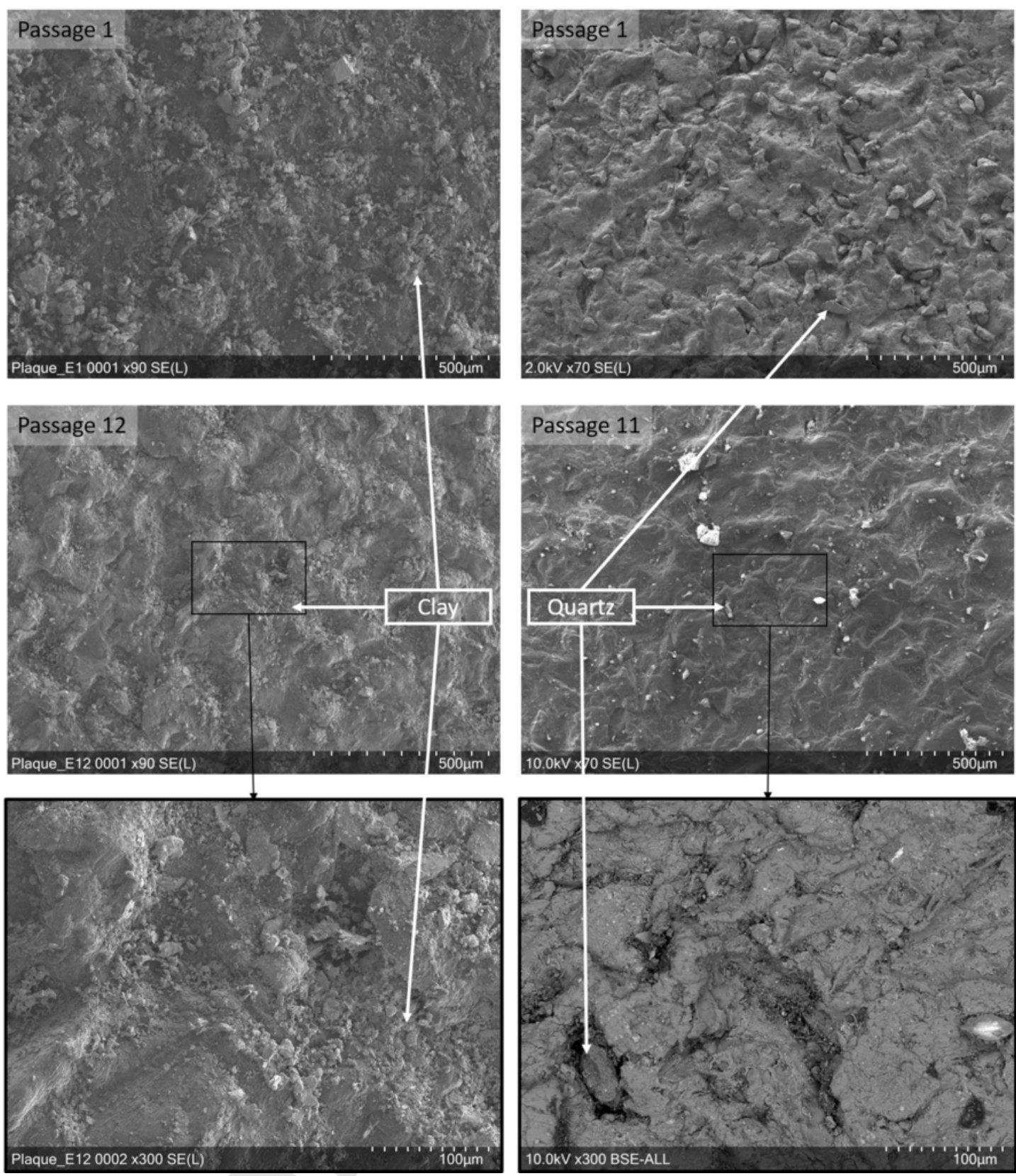

Fig. 13. Ejection of particles: left 40-50 $\mu \mathrm{m}$; right: fraction $0-100 \mu \mathrm{m}$ (SEM).

In addition to rolling and scratching behaviour, clay has an adhesive behaviour and stick to the surface after being crumbled.

Particles of quartz and clay are ejected from the contact differently. Quartz is quickly ejected because of the deformation of the tyre and the so-called pinching effect. Clay is ejected in a constant quantity.

Those different ejections and behaviour of particles, due to their diverse natures have an impact on friction and help to explain the evolution of friction through successive passes of the rubber slider on a contaminated surface. Clay has a lasting effect on friction due to its adhesive behaviour while quartz is rapidly ejected, thus showing only a brief impact on friction.

SEM analysis of aggregates showed chemical deposits on the surface and not mineral deposits. This observation questions the origin of the loss of friction for the summer ice phenomenon. To go further in the analysis of the friction generated between contaminated surface and tyre, it could be interesting to study the contamination located at the top of aggregates from the road wheel path.

\section{Acknowledgment}

The authors would like to thank gratefully Stéphane Bourron, Jean-François Le Fur, Patrick Maisonneuve, Erwann Rayssac and Christophe Ropert (technicians at IFSTTAR) for their help, suggestions and expertise which revealed fruitful.

\section{References}

[1] D.J. Wilson, The effect of rainfall and contaminants on road pavement skid resistance, 2013.

[2] M.L. Kreider, J.M. Panko, B.L. McAtee, L.I. Sweet, B.L. Finley, Physical and chemical characterization of tire-related particles: comparison of particles generated using different methodologies, Sci Total Environ 408 (2010) 652-659. 
[3] S.H. Cadle, R.L. Williams, Gas and particle emissions from automobile tires in laboratory and field studies, Rubber Chem Technol 52 (1979) 146-158.

[4] J.M. Panko, J. Chu, M.L. Kreider, K.M. Unice, Measurement of airborne concentrations of tire and road wear particles in urban and rural areas of France, Japan, and the United States, Atmos Environ 72 (2013) 192-199.

[5] M. Dannis, Rubber dust from normal wear of tires, Rubber Chem Technol 147 (1974) 1011-1037.

[6] A. Deletic, D.W. Orr, Pollution buildup on road surfaces, J Environ Eng 131 (2005) 49-59.

[7] J. Vaze, F.H.S. Chiew, Experimental study of pollutant accumulation on an urban road surface, Urban Water 4 (2002) 379-389.

[8] D. Eisenberg, The mixed effects of precipitation on traffic crashes, Accid Anal Prev 36 (2004) 637-647.

[9] Shakely RB, Henry JJ, Heinsohn RJ. Effects of pavement contaminants on skid resistance. Transp Res Rec n.d.;788:23-28.

[10] D.J. Wilson, An analysis of the seasonal and short-term variation of road pavement skid resistance, The University of Auckland, 2006.

[11] M.T. Do, V. Cerezo, H. Zahouani, Laboratory test to evaluate the effect of contaminants on road skid resistance, Proc Inst Mech Eng Part J J Eng Tribol 228 (2014) $1276-1284$.

[12] R. Mills, R.S. Dwyer-Joyce, M. Loo-Morrey, The mechanisms of pedestrian slip on flooring contaminated with solid particles, Tribol Int 42 (2009) 403-412.

[13] Y. Hichri, V. Cerezo, M.T. Do, Friction on road surfaces contaminated by fine particles: some new experimental evidences, J Eng Tribol 208-210 (2017) 1994-1996.

[14] Y. Hichri, V. Cerezo, M.T. Do, Effect of dry deposited particles on the tire/road friction, Wear 376-377 (2017) 1437-1449.

[15] S. Descartes, A. Saulot, C. Godeau, S. Bondeux, C. Dayot, Y. Berthier, Wheel flange/rail gauge corner contact lubrication: tribological investigations, Wear 271 (2011) 54-61.
[16] S. Descartes, C. Desrayaud, Y. Berthier, Experimental identification and characterization of the effects of contaminants in the wheel-rail contact, Proc Inst Mech Eng - Part F J Rail Rapid Transit 222 (2008) 207-216.

[17] O. Arias-Cuevas, Z. Li, R. Lewis, E.A. Gallardo-Hernendez, Rolling-sliding laboratory tests of friction modifiers in dry and wet wheel-rail contacts, Wear 268 (2010) 543-551.

[18] O. Arias-Cuevas, Z. Li, R. Lewis, A laboratory investigation on the influence of the particle size and slip during sanding on the adhesion and wear in the wheel-rail contact, Wear 271 (2011) 14-24.

[19] H. Heshmat, The rheology and hydrodynamics of dry powder lubrication, Tribol Trans 34 (1991) 433-439.

[20] J.W. Hall, K.L. Smith, Texturing of concrete pavements, 2008.

[21] K.W. Li, F. Meng, W. Zhang, Friction between footwear and floor covered with solid particles under dry and wet conditions, Int J Occup Saf Ergon 20 (2014) 43-53.

[22] H. Heshmat, Wear reduction systems for coal-fueled diesel engines I. The basics of powder lubrication, Wear 162-164 (1993) 508-517.

[23] D. Tabor, The hardness of metals, Oxford Cla, 1970.

[24] R. Hill, The mathematical theory of plasticity, Oxford Cla, 1950.

[25] H. Zahouani, F. Sidoroff, Rough surfaces and elasto-plastic contacts. Comptes rendus l'Academie des sci - ser IV physics, Astrophys Nor 2 (2001) 709-715, https:// doi.org/10.1016/S1296-2147(01)01213-6.

[26] E.J. Abbott, F.A. Firestone, No TitleSpecifying surface Quality: a method based on accurate measurement and comparison, J Mech Eng 55 (1933) 569-572.

[27] M. Al Hayari, P. Antoine, G. Biguenet, J. Monnet, H. Mora, Determination of shear mechanical characteristics of laminated clays at failure landslide of "la combe d'Harmalière", 50, Rev Française Géothechnique, 199071-77. 